\title{
Indoor Localization Enhancement Based on Time of Arrival Using Sectoring Method
}

\author{
Ahmed k. Daraj \\ Middle Technique University, Baghdad, Iraq \\ E-mail: ahmed.daraj@gmail.com
}

\author{
Alhamzah T. Mohammad and Mahmood F. Mosleh \\ Middle Technique University, Baghdad, Iraq \\ E-mail: \{alhamza_tm, drmahfa\}@yahoo.com
}

Received: 09 November 2019; Accepted: 16 March 2020; Published: 08 June 2020

\begin{abstract}
The indoor wireless communication in general, suffers from several challenges like, signal reflection, diffraction, and attenuation. With these problems, the error range is increased significantly and the accuracy will be lost. To address those problems, Mini Zone (MZ)e technique propos in this paper which aim to partition building into small areas lead to more simplicity and flexibility to assign suitable parameters for specific area rather than whole building. To do that, case study building separated to seven zone (A-G). Each zone has its specific characteristics related to its contents such as, objects, walls, windows and any types of materials in addition to the distance between transmitters and each zone. We took in account these specific parameters to estimate the correct position. 56 receivers ( 8 for each zone) and 3 transmitters deployed in the case study building. The Wireless Insite Package has been used to design the chosen building and measure the required parameters. The target position has been estimated depending on RSS and ToA methods The objectives of this study are to implement a dynamic system that has capabilities to estimate position under deference conditions like LOS or NLO with the same accuracy. In addition, study the suitability of TOA and RSS methods to estimate position. These objectives were done based on the proposed technique by decrease error in the whole system to an acceptable level to be $(0.293502 \mathrm{~m})$. Also, the results confirm that the TOA method was better than RSS by using propos technique.
\end{abstract}

Index Terms-Mini Zone, multipath, indoor localization, TOA, RSS.

\section{INTRODUCTION}

Nowadays, indoor localization technologies are emerging in our life, especially with smartphone applications and the Internet of Things (IoT). The main aims of new technol-ogies are to make our life easier as well as safer, so the position systems have been designed for this aim. The estimation of position is one of important applications of IoT, which advantageous to guide ourselves in airports, train stations, malls, and keep track of someone else. The electronic accessories proliferate and become a part of our daily life, so the position can be estimated by using mobile phones, laptops, tablets, wearable devices, or other smart devices. The Global Position System (GPS) is splendid in outdoor environment but indoor environment is different, so the GPS doesn't work so good [1, 2]. The concept widely uses for indoor localization is Wireless Fidelity (Wi-Fi) like in [3-6] or Wi-Fi-finger-print for more accuracy [7-9] Furthermore, in indoor environments, millimeter-wave also has been used to deal with the Fifth Generation $(5 \mathrm{G})$ as a future of communication [10-13]. In addition, Time of Arrival (ToA) [14], Angle of Arrival (AoA) [15], Direction of Arrival (DoA) [1], and Received Signal Strength (RSS) [16, 17], are also used as a prefer techniques individually or as a combination for position localization. All these methods estimate the distance between known Reference Points (RPs) and unknown targets, where the RPs could be Access Points (APs) or anchor point. The position obtained depending on methods like trilateration or triangulation $[1,16]$. However, there are many limitations and constraint which restricted the reliability and accuracy such as, huge multipath and wide band of noise emitted from other wireless communication system and electric devices. The researchers and developers have been tried to reduce error as possible like the authors in [18] tried to estimated position rely on smartphone, where they used group of volunteers in the experiment, and by using particle filter had been proposed. They reduce the error in the (PDR) method and the effect of regressive RSS. The None Line of Sight $(\mathrm{NLoS})$ is the main challenge of indoor position location, so that, the authors in [19-21], attempt to address such problem using ToA synchronization. However, many authors in [14, 15] and [22-24], focus on the mathematical side to estimate locations for indoor environments. Instead, there are several aspects that should focus on, such as, the structure of building and the state of propagation in each part of building which used as case study in the current research. In this paper, we will study the signal characteristics inside building, 
taking in to account conductivity and permittivity for each material used in design to simulate real life. Also, we propose $\mathrm{MZ}$ technique to reduce error and mitigate the regressive RSS and NLoS impact. To implement propose technique, case study building is separated into seven zones. The aim of this separation is to select a specific parameter for each zone according to its structure to enhance the reliability which leads to better accuracy of localization.

\section{RELATED WORK}

There are many localization systems constructed based on a number of methods. In this section will focus on TOA and RSS methods to deal with our study. The authors in [3] carried out a positioning system to correspond with indoor environments. such a system was constructed based on Wi-Fi technologies. The selection of this kind of wireless communications because it is supported by the smart-phones in addition to other devices. Practically, to implement such a system there are two scenarios in the system. The first scenario is collects the data and stores it in the database. This database plays the main role to be reference values in the whole building. The second scenario is the real-time measurements when the targets move inside interested area. To tracking of targets into building, the reference points was determined previously use to find targets location. After apply their proposal, the results show high effeteness on measurements leads to a highly accurate system. The authors in [4] implemented an indoor positioning system by using Wi-Fi technology. To do that path loss propagation was used to measure the required distance. The distance should measure between the known points called reference points and the targets. They suggested the trilateration method to estimate the final estimation based on the distance was measured. The authors in [5] have been constructed localization system based on the Wi-Fi approach. One of several methods to improve localization especially in indoor environments is deep learning. Basically, in localization, there is an online phase in addition to the offline phase. In the offline phase, there is a database built based on RSS measurements. According to that, they built fingerprint data based on a couple of algorithms, cross-entropy, in addition, to mean squared. In the online phase, the algorithm matching the real measurements with a database to adopt those measure-ments. The optimum measurements obtained after enhan-cements using the database show a significant decrease in error, therefore, the system will be more accurate based on the proposed algorithm compared with previous wo-rk. The high compatibility and frequency of availability encouraged the authors in [6] to use the Wi-Fi. The other thing encouraged them is the ability of $2.4 \mathrm{GHZ}$ frequency to propagate into building even with a lot of walls and objects. Three access points were deployed in the interested area to estimate the location of the target. By using method like trilateration, final location can be estimate. The obtained results show better performance. The authors in [14] implemented a localization system based on TOA for a smartphone. The concept of the proposed system is constructed rely on a light-emitting diode (LED). In this system, the smartphone recognizes the light in addition to sound waves that emits from transmitters. In this case, the measurements of Time of Flight (TOF) have been used to estimate position. The authors in this study applied their system using multitrilateration based on obtained measurements. The big challenge in estimate location based on TOA is synchronization, to address this problem, reference time which transmitted to synchronize with recoveries. At the same time modulated LED was proposed to alleviate the synchronization challenge. Furthermore, they examined the ability of VLC time synchronization in positioning. Finally, 100mm was the stander deviation in threedimension positioning in a dark room which is acceptable in practical aspects.

\section{LOCALIZATION BASED TOA}

The idea by simple way is, there are a lot of targets inside building, these targets could be mobile or stationary, also, there are several reference points RPs which known position. The number of reference point depending on the method that used to estimate position. The significant important issue is, how to measure the accuracy distance between the targets and RPs. ToA is one of these methods to estimated distance between receivers and transmitters. Let consider $\mathrm{x}=[\mathrm{x} y]^{\mathrm{T}}$ and $\mathrm{x}_{\mathrm{i}}=$ $\left[\begin{array}{ll}x_{i} & y_{i}\end{array}\right]^{\mathrm{T}}$ where $\mathrm{x}$ and $\mathrm{x}_{\mathrm{i}}$ are known and unknown position respectively. According to [1], the distance between receivers and transmitters denoted by $d_{i}$ determine by:

$$
\begin{gathered}
d_{i}=\left\|x-x_{i}\right\|=\sqrt{\left(\mathrm{x}-x_{i}\right)^{2}+\left(\mathrm{y}-y_{i}\right)^{2}} \\
i=1.2 \ldots . k
\end{gathered}
$$

Where $\mathrm{k}$, is number of receivers. Now if we assume the signal's transmitted time $\left(\mathrm{t}_{\mathrm{M}}\right)$ is equal to 0 , then ToA denoted by $t_{i}$ can determine by simple way rely on:

$$
t_{i}=\frac{d_{i}}{c} i=1.2 \ldots . k
$$

Where $c$, is speed of light, $\approx 3 \times 10^{\wedge} 8$. In addition, (1) is acceptable in ideal situation such as, with LOS environments and there is no synchronization error. However, with NLoS environments there is range of error so, according to $[22,23]$, with NLoS environments, can be written (1) as:

$$
d_{i}=|| x-x_{i} \|+\beta_{i}+m_{i}
$$

Where $\beta_{i}(\mathrm{~m})$ is positive biases, $\left(\beta_{i}=0\right)$ in LOS and $\left(\beta_{i}>0\right)$ in NLOS, $m_{i}$ is noise value. Although ToA is suffer from several challenges as mentioned above, there are some advantage as compared with other methods like the better performance in long distance [1]. To address some of drawback of ToA, a hybrid system which combine it with other algorithms such as RSS [23]. 
Where RSS is common used to estimate distance rely on path propagation as following [23-28]:

$$
P L(d)=P l o-b_{i}-10 \gamma \log 10 \frac{\left\|x-x_{i}\right\|}{d 0}+s
$$

Where Plo is reference path loss and measure in reference distance that recommended in one meter, $\gamma$ is path loss which is different rely on environment around targets, $\mathrm{S}$ is normal random variable. In other hand, the receive power determine as following [21]:

$$
\mathrm{PRX}=\mathrm{PTX}-10 \gamma \log (d)-S
$$

Where $\mathrm{P}_{\mathrm{RX}}$ and $\mathrm{P}_{\mathrm{TX}}$ are the received and transmitted power respectively. With advantage of both RSS and ToA, the authors in [23], have been taken the advantage of one to address the problem with the other:

$$
\begin{aligned}
& \left(d_{i}\right)^{R S S}=10^{\frac{p_{o^{-}}-p_{i^{-}} \frac{b^{\wedge} \max }{2}}{10 \gamma}} \\
& \left(d_{i}\right)^{T O A}=d_{i}-\frac{\beta}{2}^{\max }
\end{aligned}
$$

When distance between references and targets is available then trilateration or triangulation methods use to estimate position [29, 30], as shown in Fig.1.

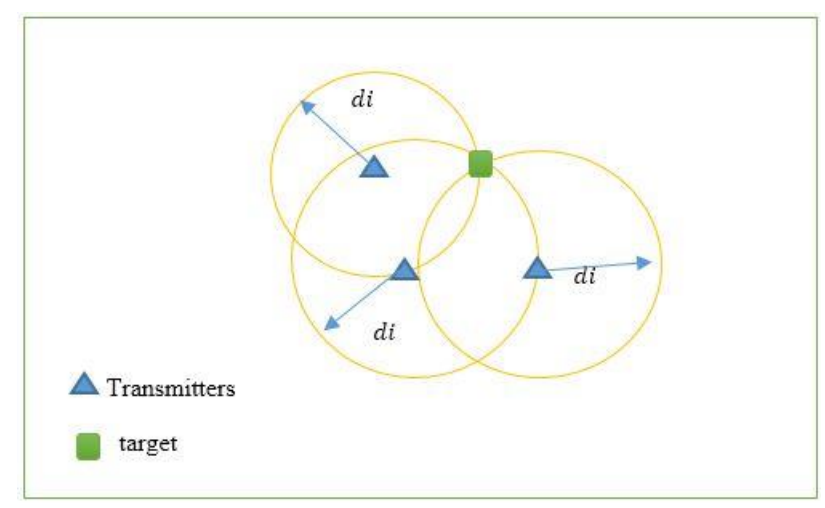

Fig.1. Estimate position using trilateration methods

Where $d_{i}$ determine by ToA or RSSI method and represnted the raduis of circle, the position of target is the intersection between three circles. In addition, there is other method of trilareration by using 4 transmitters or more to estimate the targets location by multi-trilatration for more accuracy. However, there are consederation in poistion systems design sush as, number of transmitters, complixty and cos. To implement our proposal, TOA and RSS obtained by simulation software will discuss in next section. Therefore, there is ability to apply (6) and (7) based on obtaining measurements. But the applying will be supported by MZ technique to achieve better performance.

\section{CASE STUdy}

In this paper, case study building designed based on Wireless Insite Package. Such building is the campus of electrical engineering technical college as shown in Fig.2a. The selected area within such college is the first floor which is divided into seven segments. The deployed receivers are 56 ( 8 for each zone) with height of $1.5 \mathrm{~m}$ in addition to 3 transmitters with height of $2 \mathrm{~m}$. The position of transmitters is optimized by trying three times and select the better one to alleviate the main cause of error such as, reflection, diffraction and signal attenuation. The RSS in first two positions was unstable or useless sometimes subsequently, the error range increase with regressive RSS. Third position as shown in Fig.2b., is better than first two positions in term of RSS stability. All these problems happen in NLoS environments as shown in Fig.3. The contents of case study building are deference from place to another such as, walls, doors, windows, and the type of each of material. According to that, the impact of material on signal propagation is deference from place to another. Therefore, case study building has been separated to seven zones (A-G) to select suitable parameters for each zone. The characteristics of transmitter's and receiver's antenna are illustrating in Table 1., with opera-ting frequency of 2.4 GHZ.

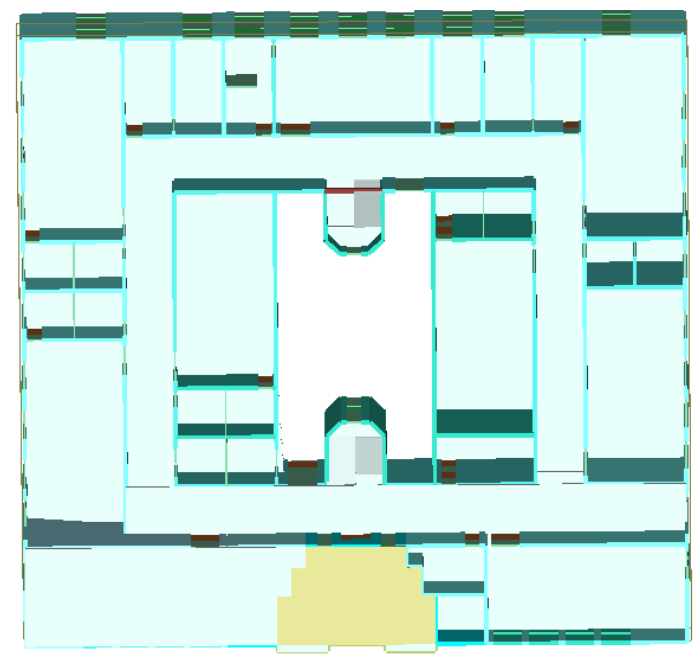

Fig.2a. Case study building

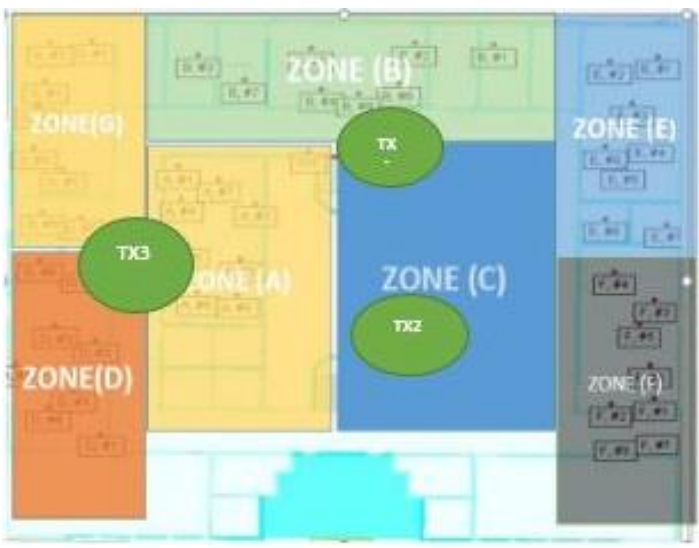

Fig.2b. Mini Zones (A-G) 


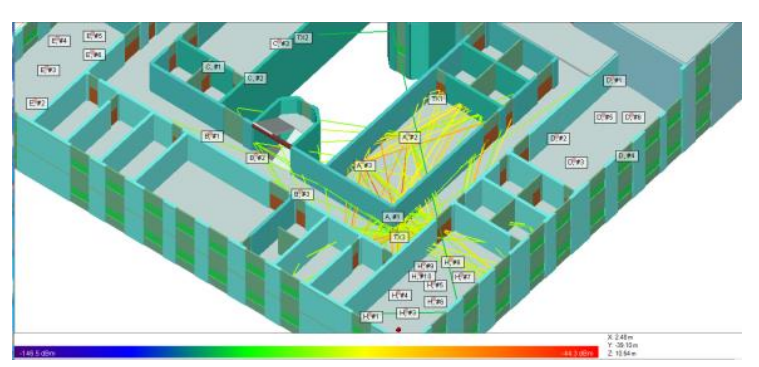

Fig.3. Multipath propagation

Table 1. The characteristics of antennas

\begin{tabular}{|c|c|c|}
\hline $\begin{array}{c}\text { Antenna } \\
\text { properties }\end{array}$ & $\begin{array}{c}\text { Transmitter } \\
\text { Antenna }\end{array}$ & $\begin{array}{c}\text { Receiver } \\
\text { Antenna }\end{array}$ \\
\hline Antenna type & Omni-Directional & Omni-Directional \\
\hline Input Power (dBm) & 12 & - \\
\hline Gain (dBi) & 7.5 & 1.5 \\
\hline E-Plane HPBW & $10^{\circ}$ & $90^{\circ}$ \\
\hline Waveform & Sinusoid & Sinusoid \\
\hline Temperature (k) & 293 & 293 \\
\hline Polarization & $\mathrm{V}$ & $\mathrm{V}$ \\
\hline $\begin{array}{c}\text { Received Threshold } \\
(\mathrm{dBm})\end{array}$ & -140 & -140 \\
\hline
\end{tabular}

In Table 1., there is ability in wireless Insite software to setup the required parameterise to deal with real antennas. Such parameterise is selected based on transmitters we used such as the input power is $12 \mathrm{dBm}$ in addition to Sinusoid wave.

The conductivity and permittivity for each material calculated depending on some parameters. According to [31], the conductivity denoted by $(\sigma)$, can be determine as following:

$$
\sigma=c \times f^{d}
$$

The constant $c$ and $d$ are illustrating in Table 2. The permittivity $(\eta)$ is determine as following:

$$
\eta=a \times \mathrm{f}^{\mathrm{b}}
$$

The constant $a$ and $b$ are related to each material used to construct the chosen building which are listed in Table 3 [31].

Table 2. The constant (c and d) that used in (9).

\begin{tabular}{|c|c|c|}
\hline Material type & Conductivity & Permittivity \\
\hline Concrete & 0.0926 & 5.31 \\
\hline Brick & 0.1079 & 3.75 \\
\hline Wood & 0.0134 & 1.99 \\
\hline Glass & 0.0122 & 6.27 \\
\hline
\end{tabular}

Table 3. The constant ( $\mathrm{a}$ and $\mathrm{b}$ ) that used in (10).

\begin{tabular}{|c|c|c|}
\hline Material type & a & b \\
\hline Concrete & 5.31 & 0 \\
\hline Brick & 3.75 & 0 \\
\hline Wood & 1.99 & 0 \\
\hline Glass & 6.27 & 0 \\
\hline
\end{tabular}

In Table 2., and Table 3., clearly noted the constants of some materials, those constants is standers values defined in [31]. Moreover, the constant $b$ in Table 3., equal to zero therefore, all permittivity equal to constant $a$ according to (9).

By apply (8) and (9), the resultant conductivity and permittivity for $2.4 \mathrm{GHZ}$ frequency are listed in Table 4 .

Table 4. The Permittivity \&Conductivity for $2.4 \mathrm{GHZ}$ frequency

\begin{tabular}{|c|c|c|}
\hline Material type & $\mathrm{c}$ & $\mathrm{d}$ \\
\hline Concrete & 0.0326 & 0.8095 \\
\hline Brick & 0.038 & 0 \\
\hline Wood & 0.0047 & 1.0718 \\
\hline Glass & 0.0043 & 1.1925 \\
\hline
\end{tabular}

\section{RESULTS \& DisCUSSION}

The obtaining results compared with the existing techniques using ToA and RSS. The proposed technique labeled as Mini Zone ToA (MZ-ToA) and (MZ-RSS). The main performance metric has been used is error distance defined as, $\epsilon=\left\|d-d_{i}\right\|$, where $d$ is real distance and $d_{i}$ is estimate distance. Fig.4., illustrates the comparison between the two techniques mentioned above. The error has been improved to be $(0.293502 \mathrm{~m})$ by using the propose MZ-ToA technique, while it was $(1.026669 \mathrm{~m})$ using ToA only.

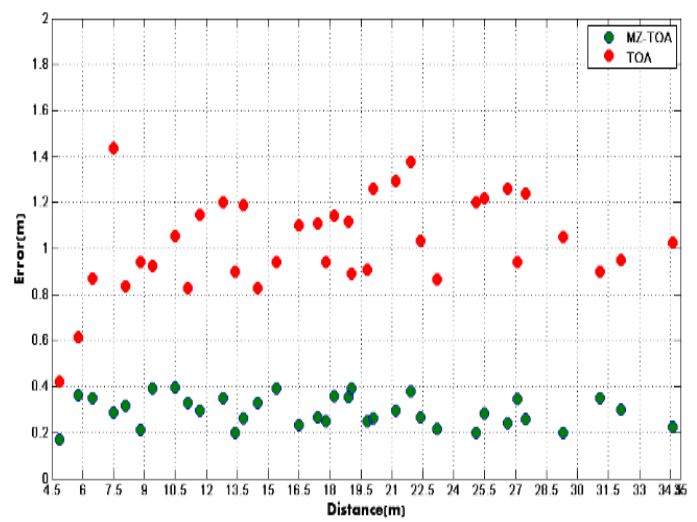

Fig.4. The comparison between TOA and MZ- TOA technique

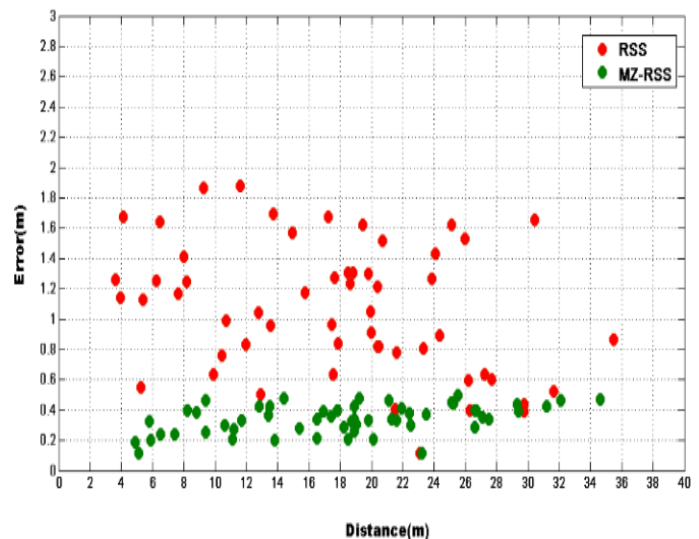

Fig.5. The comparison between RSS and MZ-RSS technique. 
In addition, the second technique has been improved is estimation position based on RSS. The comparison between MZ-RSS and RSS only is shown in Fig.5. The average distance error has been decreased by using MZRSS from $(1.026273 \mathrm{~m})$ to $(0.339659 \mathrm{~m})$.

The total area of case study building is $\left(1946 \mathrm{~m}^{2}\right)$. The challenge facing us is the deference distance between receivers and transmitters in addition to structure of each area. These problems have been alleviated by separated zones and chose convenient parameters as shown in Table 5.

Table 5. The selected parameters that selected\& average distance error.

\begin{tabular}{|c|c|c|c|c|}
\hline Zone & $\mathrm{m}$ & $\mathrm{S}$ & $\gamma$ & $\begin{array}{c}\text { Average distance } \\
\text { error(m) }\end{array}$ \\
\hline $\mathrm{A}$ & 2 & 12.55 & 4 & 0.3357 \\
\hline $\mathrm{B}$ & 1.25 & 11.22 & 3 & 0.294925 \\
\hline $\mathrm{C}$ & 2.75 & 12.60 & 5 & 0.293363 \\
\hline $\mathrm{D}$ & 1.5 & 13.10 & 4 & 0.3253 \\
\hline $\mathrm{E}$ & 1.75 & 10.75 & 5 & 0.27235 \\
\hline $\mathrm{F}$ & 2.25 & 11 & 4 & 0.270275 \\
\hline $\mathrm{G}$ & 1 & 13 & 5 & 0.29805 \\
\hline
\end{tabular}

Where $\gamma$ is path loss exponent can be assigned to 2 in LOS and 6 in harsh environments. The variable $\mathrm{S}$ is lognormal shadowing between (2-14) assigned based on environments after trying many values to select the suitable value. Finally, $\mathrm{m}$ is random variable use in TOA method based on expectation error. By assigned suitable parameters for each zone, our system was more flexible to deal with every scenario and the results are fewer errors.

Nonetheless, position of transmiters is senstive issiue in indoor localization. As shown in Fig.5., the RSS is unstable in posision one and two. However, position three is close from exact RSS. The regrisive RSS increse error range, so the position three is better one.

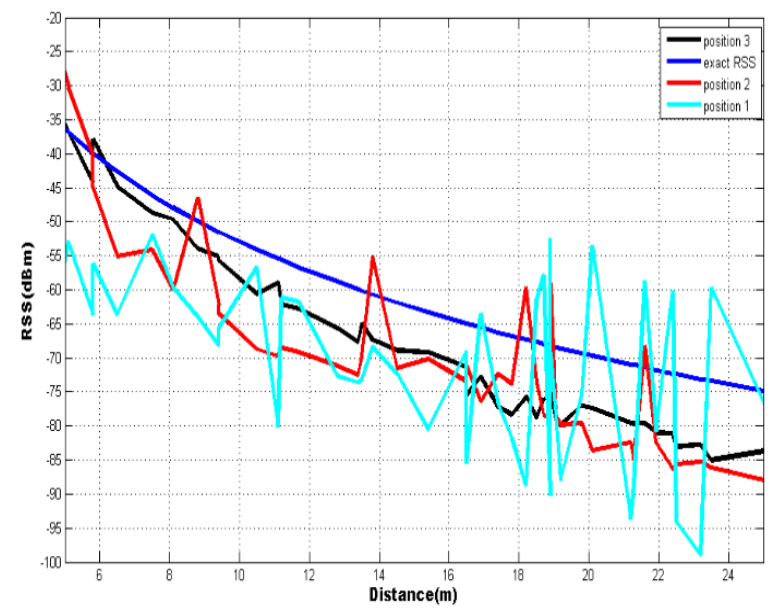

Fig.6. The RSS in different transmitters position

To confirm effeteness of propos technique, Table 6., listed the results obtained in [2] compared with our technique. The comparison confirm that the select of Wi$\mathrm{Fi}$ technology is prefer chose according to performance and availability. In addition, the authors in [2] selected two environments and the results show different percentage of errors between them. This problem solved in our technique by take in consideration the impact of materials for each zone leaded to close error in whole building.

Table 6. Comparison between MZ technique and other work.

\begin{tabular}{|c|c|c|c|c|c|c|}
\hline \multirow{2}{*}{\multicolumn{2}{|c|}{ Environments }} & \multicolumn{5}{|c|}{$\begin{array}{l}\text { Average error }(\mathrm{m}) \text { in distance }(1-5 \mathrm{~m}) \\
\text { based on RSS }\end{array}$} \\
\hline & & Wi-Fi & BLE & & Zigbee & LoRaWAN \\
\hline \multicolumn{2}{|c|}{1} & 0.843 & 0.661 & & 0.882 & 0.846 \\
\hline \multicolumn{2}{|c|}{2} & 0.486 & 0.844 & & 0.911 & 1.534 \\
\hline \multicolumn{2}{|c|}{ Overall } & 0.6645 & 0.753 & & 0.896 & 1.190 \\
\hline \multicolumn{7}{|c|}{$\begin{array}{l}\text { Average error }(\mathrm{m}) \text { in distance }(1-35 \mathrm{~m}) \text { based on propos MZ- RSS } \\
\text { technique using Wi-Fi only in } 7 \text { environments }\end{array}$} \\
\hline 0.335 & 0.294 & 0.293 & 0.325 & 0.272 & \begin{tabular}{l|l}
0.270 \\
\end{tabular} & 0.298 \\
\hline \multicolumn{7}{|c|}{ Overall } \\
\hline \multicolumn{7}{|c|}{0.298} \\
\hline
\end{tabular}

From Table 6., the average error in [2] was $(0.664 \mathrm{~m})$ while our technique $(0.298 \mathrm{~m})$. In addition, two environments in distance (1-5m) measured in [2], in contrast, our measurements were $(1-35 \mathrm{~m})$ therefore more complexity in environments.

\section{CONCLUSIONS}

In this paper, a proposed $\mathrm{MZ}$ technique is used with each RSS and ToA in order to estimate the position locations of 56 targets deployed randomly in a selected building. Such building is simulated using Wireless Insite package with real dimensions to apply the proposed algorithm in order to show effectiveness for position locations. Three transmitters based $2.4 \mathrm{GHZ}$ are installed in a chosen place within case study building. The results show that a significantly decreases in error which measure as the differences between actual and estimated position are obtained using the proposed $\mathrm{MZ}$ combined with RSS and ToA. Also, the result illustrated that such error is improved from $(1.02669 \mathrm{~m})$ using ToA only to $(0.293502 \mathrm{~m})$ using the proposed MZ-ToA. In contrast, the MZ-RSS evolve the errors from (1.026273m) to $(0.339659 \mathrm{~m})$ which confirm that MZ-ToA is slightly outperform MZ-RSS. The objectives of this study are to implement a dynamic system that has capabilities to estimate position under deference conditions like LOS or NLO with the same accuracy. In addition, study the suitability of TOA and RSS methods to estimate position. These objectives were done based on the proposed technique by decrease error in the whole system to an acceptable level. Also, the results confirm that the TOA method was better than RSS by using propos technique.

\section{REFERENCES}

[1] Zekavat, Reza, and R. Michael Buehrer. Handbook of position location: Theory, practice and advances. $1^{\text {st }} \mathrm{ed}$., Vol. 27. John Wiley \& Sons, 2011.

[2] B. Jia, B. Huang, H. Gao, W. Li, and L. Hao, "Selecting Critical Wi-Fi APs for Indoor Localization Based on a 
Theoretical Error Analysis," IEEE Access, vol. 7, pp. 36312-36321, 2019.

[3] C. Chen, Y. Chen, H. Q. Lai, Y. Han, and K. J. R. Liu, "High accuracy indoor localization: A Wi-Fi based approach," ICASSP, IEEE Int. Conf. Acoust. Speech Signal Process. - Proc., vol. 2016-May, pp. 6245-6249, 2016.

[4] B. Kim, W. Bong, and Y. C. Kim, "Indoor localizationfor Wi-Fi devices by cross-monitoring AP and weighted triangulation," 2011 IEEE Consum. Commun. Netw. Conf. CCNC'2011, pp. 933-936, 2011.

[5] H. Chih, Y. Chen, T. Juang, and Yi-Ting Wu. "An adaptive wi-fi indoor localization scheme using deep learning." In 2018 IEEE Asia-Pacific Conference on Antennas and Propagation (APCAP), pp. 132-133. IEEE, 2018

[6] S. A. Yuvaraj, and L. C. Siddanna, "High performance implementation of RSSI based Wi-Fi location tracker for android applications," J. Theor. Appl. Inf. Technol., vol. 71, no. 1, pp. 97-106, 2015.

[7] P. Jiang, Y. Zhang, W. Fu, H. Liu, and X. Su, "Indoor mobile localization based on Wi-Fi fingerprint's important access point," Int. J. Distrib. Sens. Networks, vol. 2015, 2015.

[8] E. Navarro, B. Peuker, M. Quan, A. C. Clark, and J. Jipson, "Wi-Fi Localization Using RSSI Fingerprinting," pp. 1-6, 2010.

[9] Z. E. Khatab, A. Hajihoseini, and S. A. Ghorashi, "A Fingerprint Method for Indoor Localization Using Autoencoder Based Deep Extreme Learning Machine," IEEE Sensors Lett., vol. 2, no. 1, pp. 1-4, 2017.

[10] M. M. Abdulwahid, O. A. Shareef, M. F. Mosleh, and R. A. Abd-Alhmeed "A Comparison between Different Cband and mmWave band Frequencies for Indoor Communication," Journal of Communications, vol. 10, no. 3, pp. 5663-5679, 2019.

[11] M. El Hajj, G. Zaharia, G. El Zein, H. Farhat, and S. Sadek, "Millimeter-Wave Propagation Measurements at $60 \mathrm{GHz}$ in Indoor Environments," 2019 Int. Symp. Signals, Circuits Syst., pp. 1-4, 2019.

[12] Z. Lin, T. Lv, and P. T. Mathiopoulos, "3-D Indoor Positioning for Millimeter-Wave Massive MIMO Systems," IEEE Trans. Commun., vol. 66, no. 6, pp. 2472-2486, 2018.

[13] I. A. Hemadeh, K. Satyanarayana, M. El-Hajjar, and L. Hanzo, "Millimeter-Wave Communications: Physical Channel Models, Design Considerations, Antenna Constructions, and Link-Budget," IEEE Commun. Surv. Tutorials, vol. 20, no. 2, pp. 870-913, 2018.

[14] Akiyama, Takayuki, Masanori Sugimoto, and Hiromichi Hashizume."Time-of-arrival-based smartphone localization using visible light communication." In 2017 International Conference on Indoor Positioning and Indoor Navigation (IPIN), pp. 1-7. IEEE, 2017.

[15] Y. Hou, X. Yang, and Q. H. Abbasi, "Efficient AoABased Wireless Indoor Localization for Hospital Outpatients Using Mobile Devices," Sensors (Basel)., vol. 18, no. 11, pp. 1-17, 2018.

[16] S. Sadowski and P. Spachos, "RSSI-Based Indoor Localization with the Internet of Things," IEEE Access, vol. 6, pp. 30149-30161, 2018.

[17] O. A. S. Al-ani, K. S. Muttair, and M. F. Mosleh, "Outdoor Transmitter Localization using Multiscale Algorithm," International Journal of Simulation Systems, Science \& Technology., pp. 1-7, 2019.

[18] H. Xia, J. Zuo, S. Liu, and Y. Qiao, "Indoor Localization on Smartphones Using Built-In Sensors and Map
Constraints," IEEE Trans. Instrum. Meas., vol. 68, no. 4, pp. 1189-1198, 2019.

[19] S. Wu, S. Zhang, and D. Huang, "A TOA-Based Localization Algorithm with Simultaneous NLOS Mitigation and Synchronization Error Elimination," IEEE Sensors Lett., vol. 3, no. 3, pp. 1-4, 2019.

[20] B. Al-Qudsi, M. El-Shennawy, Y. Wu, N. Joram, and F. Ellinger, "A hybrid TDoA/RSSI model for mitigating NLOS errors in FMCW based indoor positioning systems," 2015 11th Conf. Ph.D. Res. Microelectron. Electron. PRIME 2015., no. 1, pp. 93-96, 2015.

[21] H. Cho, J. Ji, Z. Chen, H. Park, and W. Lee, “Accurate Distance Estimation between Things: A Self-correcting Approach," Open J. Internet Things, vol. 1, no. 2, pp. 1927,2015

[22] S. Tomic, M. Beko, M. Tuba, and V. M. F. Correia, "Target Localization in NLOS Environments Using RSS and TOA Measurements," IEEE Wirel. Commun. Lett., vol. 7, no. 6, pp. 1062-1065, 2018.

[23] S. Tomic and M. Beko, "Target localization via integrated and segregated ranging based on RSS and TOA measurements," Sensors (Switzerland), vol. 19, no. 2, pp. $1-20,2019$.

[24] S. Tomic, M. Beko, R. Oliveira, L. Bernardo, N. Bacanin, and M. Tuba, "On Hybrid RSS/TOA Target Localization in NLOS Environments," 2018 14th Int. Wirel. Commun. Mob. Comput. Conf. IWCMC 2018, pp. 1471-1476, 2018.

[25] S. Chang, Y. Li, X. Yang, H. Wang, W. Hu, and Y. Wu, "A novel localization method based on RSS-AOA combined measurements by using polarized identity," IEEE Sens. J., vol. 19, no. 4, pp. 1463-1470, 2019.

[26] S. Tiwari et al., "Practical result of wireless indoor position estimation by using hybrid TDOA/RSS algorithm," Can. Conf. Electr. Comput. Eng., no. 1, pp. 15,2010 .

[27] D. Wu, Y. Xu, and L. Ma, "Research on RSS based indoor location method," KESE 2009 - 2009 Pacific-Asia Conf. Knowl. Eng. Softw. Eng., pp. 205-208, 2009.

[28] S. Tomic and M. Beko, "A robust NLOS bias mitigation technique for RSS-TOA-based target localization," IEEE Signal Process. Lett., vol. 26, no. 1, pp. 64-68, 2019.

[29] Y. Wang, X. Yang, Y. Zhao, Y. Liu, and L. Cuthbert, "Bluetooth positioning using RSSI and triangulation methods," 2013 IEEE 10th Consum. Commun. Netw. Conf. CCNC 2013, pp. 837-842, 2013.

[30] M. Shchekotov, "Indoor Localization Method Based on Wi-Fi Trilateration Technique," Proceeding 16Th Conf. Fruct Assoc., pp. 177-179, 2014.

[31] ITU-R, Effects of building materials and structures on radiowave propagation above about $100 \mathrm{MHz}$ P Series Radiowave propagation, Recomm. ITU-R P.2040, vol. 1, 2013.

\section{Authors' Profiles}

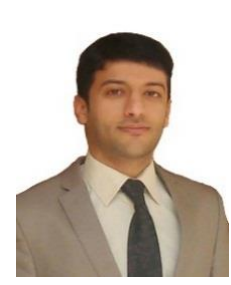

Ahmed K. Daraj Received a Diploma degree from the technical institute, BasraIraq in 2010 in the field of electronic Technique and B.Sc. in computer engineering techniques (CET) from $\mathrm{Al}$ kunooz College University (KCU), BasraIraq in 2017. Works in "Alshuhadaa foundation" since 2011 and as a head of information technologies department since 2012. He works with networking solution in several companies. Currently, he studies 
M.Sc. in CET from Electrical Engineering Technical college, Baghdad-Iraq. His research includes, Indoor localization, indoor communication, 5G communication, and multipath propagation investigation.

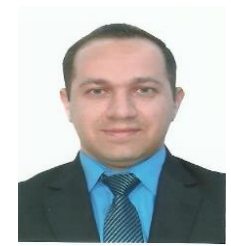

Alhamzah T. Mohammed Received his B.Sc. in Electronics and Communications Department /College of Engineering/ AlNahrain University (Baghdad, Iraq), 2004 received the M.Sc. degree in Electronics and Communications Department /college of Engineering/ Al-Nahrain University (Baghdad, Iraq), 2008, he worked a lecturer, researcher and training supervisor, Dep. of Electronic in Institute of Technology- Baghdad and College of Electrical Engineering Techniques. Currently he is head of Computer Communications Networks Branch, in Department of Computer Technology Engineering.

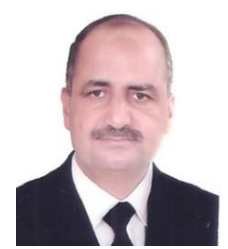

Mahmood F. Mosleh received a Diploma degree from the institute of Technology/ Baghdad in 1978 in the field of electronic Technique; he worked in the same institute up to 1992 as a Technical Trainer. He awarded B.Sc., M.Sc. and Ph.D. degrees from University of Technology in 1996, 1999 and 2008 respectively. Through those periods and up to now, he worked as advanced Trainer, Assistance Lecturer, Lecturer, Assistance Professor and Professor in the Electrical Engineering Technical College/ Baghdad. He published about 52 papers in various Journals in the field of Communications Engineering. He has a 3 patents in designing a new technique. He supervised $11 \mathrm{MSc}$ and $2 \mathrm{PhD}$ students. Currently he is the Chairman of the Iraqi International Electro-Technical Committee.

How to cite this paper: Ahmed k. Daraj, Alhamzah T. Mohammad, Mahmood F. Mosleh, "Indoor Localization Enhancement Based on Time of Arrival Using Sectoring Method", International Journal of Intelligent Systems and Applications(IJISA), Vol.12, No.3, pp.1-7, 2020. DOI: 10.5815/ijisa.2020.03.01 